\title{
Long-term results of surgery for lumbar spinal stenosis: a randomised controlled trial
}

\author{
Pär Slätis • Antti Malmivaara $\cdot$ Markku Heliövaara • \\ Päivi Sainio • Arto Herno · Jyrki Kankare • Seppo Seitsalo · \\ Kaj Tallroth · Veli Turunen · Paul Knekt $\cdot$ Heikki Hurri
}

Received: 15 February 2010/Revised: 18 November 2010/ Accepted: 5 December 2010/Published online: 15 January 2011

(c) Springer-Verlag 2011

\begin{abstract}
We randomised a total of 94 patients with longstanding moderate lumbar spinal stenosis (LSS) into a surgical group and a non-operative group, with 50 and 44 patients, respectively. The operative treatment comprised undercutting laminectomy of stenotic segments, augmented with transpedicular-instrumented fusion in suspected lumbar instability. The primary outcome was the Oswestry disability index (ODI), and the other main outcomes included assessments of leg and back pain and self-reported walking ability, all based on questionnaire data from 85 patients at the 6-year follow-up. At the 6-year follow-up, the mean difference in ODI in favour of surgery was 9.5 (95\% confidence interval $0.9-18.1, P$-value for global difference 0.006 ), whereas the intensity of leg or back pain
\end{abstract}

P. Slätis · S. Seitsalo · K. Tallroth · H. Hurri ORTON Orthopaedic Hospital, Invalid Foundation, Helsinki, Finland

\section{A. Malmivaara $(\square)$}

Centre for Health Economics,

National Institute for Health and Welfare,

P.O. Box 30, 00271 Helsinki, Finland

e-mail: antti.malmivaara@thl.fi

M. Heliövaara · P. Sainio · P. Knekt

National Institute for Health and Welfare,

P.O. Box 30, 00271 Helsinki, Finland

\section{A. Herno · V. Turunen}

Department of Orthopaedic Surgery,

Kuopio University Hospital, Kuopio, Finland

J. Kankare

Department of Orthopaedic and Trauma Surgery (JK),

Helsinki University Hospital, Helsinki, Finland did not differ between the two treatment groups any longer. Walking ability did not differ between the treatment groups at any time. Decompressive surgery of LSS provided modest but consistent improvement in functional ability, surpassing that obtained after non-operative measures.

Keywords Spinal stenosis - Surgical treatment . Non-operative treatment $\cdot$ Randomised controlled trial

\section{Introduction}

Cumulative data reveal that patients with severe lumbar spinal stenosis (LSS) associated with excruciating leg and back pain and neural dysfunction benefit from decompressive surgery $[1,3,4,8,12,14-16,21]$. The results indicate that the more severe the structural changes and the dysfunction are, the more advantageous the operative measures will be. The results also indicate that the outcomes after surgery slowly deteriorate over time.

There is, however, a growing subgroup of patients with a less severe clinical picture, characterized by a narrow lumbar spinal canal and long-standing pain in the legs and back. The borderline between severe and moderate cases of LSS has not been clearly defined, although recently the effectiveness of decompressive surgery with or without fusion for moderate spinal stenosis has been assessed in randomised controlled trials [2, 18, 22, 23]. Weinstein et al. [22] have conducted separate trials for spinal stenosis with and without degenerative spondylolisthesis.

The aim of the present randomised trial was to evaluate the long-term efficacy of operative treatment as compared with results obtained by non-operative measures in patients with moderate LSS. 


\section{Methods}

\section{Recruitment of subjects}

The patients were directed from healthcare centres or local hospitals to the contributing university hospitals. Once there, an experienced orthopaedic surgeon or neurosurgeon examined and assessed them. Recruitment took place between December 1997 and March 2001.

All patients received oral and written information regarding the treatment of spinal stenosis. We obtained written, informed consent from each of them. In the event of an exacerbation of their condition during non-operative treatment, they were given the opportunity to enter the surgical group. They were free to discontinue their participation at any time during the planned two- to six-year follow-up period.

\section{Inclusion and exclusion criteria}

The inclusion criteria included back pain radiating to the lower limbs or buttocks; fatigue and loss of sensation in the lower limbs aggravated by walking; persistent pain without progressive neurologic dysfunction; spinal narrowing, with the sagittal diameter being less than $10 \mathrm{~mm}$; the crosssectional dural sac being less than $75 \mathrm{~mm}^{2}$; the severity of the disease justifying either surgical or non-operative treatment.

The strict selection of patients for inclusion in this trial should be noted. We focused our attention on patients with long-standing back and leg pain and impaired functional ability and patients who showed concomitant signs of neural dysfunction. All patients had a narrowing of the lumbar spinal canal at one or several levels (minimal transverse area of the dural sac $<75 \mathrm{~mm}^{2}$ ) and all patients were considered to suffer predominantly from LSS [2, 4, $15,18,20]$. The mean age of 63 years in the present study corresponds to age levels reported in current studies on LSS [1-4, 13, 14].

The overall clinical condition of each patient, as assessed by an experienced spine surgeon, was not serious enough to require immediate surgical intervention. But it was serious enough to challenge the continuation of conservative treatment. This may be regarded to represent the term moderate when assessing severity of LSS. Medically and ethically, we considered both operative and nonoperative modalities of treatment eligible. We informed the patients on both the nature of their ailment and on the aims and content of the present study. Ninety-four patients gave their consent to contribute to the randomised trial [18].

The following conditions did not prevent inclusion: radiographic instability of the lumbar spine; degenerative spondylolisthesis; sick leave or early retirement because of degenerative LSS; mild motor or sensory impairment in the lower limbs; well-functioning hip or knee prosthesis.

The main exclusion criteria included severe LSS with intractable pain and progressive neurologic dysfunction, requiring surgical treatment; mild LSS characterized by narrowing of the lumbar spinal canal, but clinical signs and symptoms weak enough to justify being excluded from the surgical intervention; psychiatric disorders and alcoholism.

The details of the inclusion and exclusion criteria are described in our previous report [18].

\section{Randomisation}

We randomised the patients into either a surgical group or a non-operative group comprising 50 and 44 patients, respectively. This took place at the central office in order to ensure that the allocation process remained private; this randomisation was based on computer-generated random blocks of variable size for each contributing hospital.

\section{Baseline and outcome assessments}

Before the randomisation, and at all follow-up visits 6,12 and 24 months later, the patients filled in a standard questionnaire and underwent a standardized clinical assessment, radiographic examinations and a walkingcapacity test. We obtained the 72-month follow-up data via questionnaires sent to the patients; 44 patients in the surgical group and 37 in the non-operative group returned the questionnaire (Fig. 1).

The baseline questionnaire gathered information on demographic factors, symptoms and functional disability (Table 1). The primary outcome measure was the Oswestry disability index (ODI), where 0 indicates no disability and 100 indicates the worst possible disability [11]. We surveyed the intensity of pain in the leg and lower back during walking using a numerical scale from 0 (no pain) to 10 (worst possible pain). We assessed walking ability by asking the distance in metres that the patient could walk on even ground without a break.

Radiographic examinations at baseline consisted of plain radiographs of the lumbar spine, myelography, computed tomography and/or magnetic resonance imaging. We took myelography images of the patients in supine, prone and vertical postures, including extension. We measured the sagittal diameter of the spinal canal and the transverse area of the dural sac on all segmental levels between $\mathrm{L} 1$ and $\mathrm{S} 1$.

\section{Interventions}

In the surgical group, we performed segmental decompression and an undercutting facetectomy of the affected 


\begin{tabular}{|c|c|}
\hline Rando & $(n=94)$ \\
\hline $\begin{array}{l}\text { Decompressive surgery } \\
(\mathbf{n}=\mathbf{5 0}) \\
-45 \text { were operated on } \\
-4 \text { were not operated on } \\
\text { because of relief in pain } \\
-1 \text { withdrew }\end{array}$ & $\begin{array}{l}\begin{array}{l}\text { Non-operative treatment } \\
(\mathbf{n}=\mathbf{4 4})\end{array} \\
\text { - } 40 \text { received conservative } \\
\text { treatment } \\
\text { - } 4 \text { received conservative } \\
\text { treatment }+ \text { operation because }\end{array}$ \\
\hline $\begin{array}{l}\text { 6-month follow-up (n=44) } \\
\text { - lost in the follow up (6): } \\
\text { protocol violation (5) } \\
\text { withdrew (1) } \\
\text { 12-month follow-up (n=48) } \\
\text { - lost in the follow up (2): } \\
\text { withdrew (1) } \\
\text { moved abroad (1) } \\
\text { 24-month follow-up (n=47) } \\
\text { - lost in the follow up (3): } \\
\text { withdrew (1) } \\
\text { moved abroad (1) } \\
\text { died (1) } \\
\text { 72-month follow-up (n=46) } \\
\text { - lost in the follow up (4): } \\
\text { died (3) } \\
\text { uncomplete data (1) }\end{array}$ & $\begin{array}{l}\text { 6-month follow-up (n=41) } \\
\text { - lost in the follow up (3): } \\
\text { protocol violation (1) } \\
\text { lack of efficacy (1) } \\
\text { mental disorder (1) } \\
\text { 12-month follow-up (n=41) } \\
\text { - lost in the follow up (3): } \\
\text { mental disorder (1) } \\
\text { stroke (2) } \\
\text { 24-month follow-up (n=40) } \\
\text { - lost in the follow up (4): } \\
\text { mental disorder (1) } \\
\text { stroke (1) } \\
\text { died (2) } \\
\text { 72-month follow-up (n=39) } \\
\text { - lost in the follow up (5): } \\
\text { died (3) } \\
\text { uncomplete data (1) } \\
\text { lost in the follow-up (1) }\end{array}$ \\
\hline
\end{tabular}

Fig. 1 Flow of the patients through each stage of the study

area. We performed decompressive surgery on level L2-3 in three instances, on level 3-4 in 26 instances, on level 4-5 in 44 instances and on level L5-S1 in zero instances. The operation was done on one level in 17 instances, on two levels in 23 instances and on more than two levels in five instances. We treated the presence or risk of lumbar instability, at the surgeon's discretion, by fusion of the involved segments, which, in all ten cases, was augmented by transpedicular instrumentation.

In the non-operative treatment group, a physiatrist followed the patients throughout the follow-up periods, assessing the need for individual treatment. The physiatrist prescribed non-steroidal anti-inflammatory drugs to the patients when indicated and referred them to physiotherapists. A physiotherapist saw the patients one to three times, in addition to the standard visit at each follow-up meeting.

The physiotherapist gave all patients a printed brochure describing the nature of spinal stenosis, the characteristic symptoms and signs of the disease, and the principles of activation and physical training.

The physiotherapist encouraged the patients to use their back in a normal way and taught them pain-relieving body postures as well as basic ergonomics relating to lifting and carrying. Individually structured programmes included
Table 1 Baseline characteristics of 94 patients with spinal stenosis who randomly received surgical or non-operative treatment

\begin{tabular}{|c|c|c|}
\hline Characteristics & $\begin{array}{l}\text { Non-operative } \\
(n=44)\end{array}$ & $\begin{array}{l}\text { Surgical } \\
(n=50)\end{array}$ \\
\hline Age (year) & $62 \pm 9$ & $63 \pm 9$ \\
\hline Female sex $(\%)$ & 55 & 78 \\
\hline Body mass index $\left(\mathrm{kg} / \mathrm{m}^{2}\right)$ & $28 \pm 4$ & $27 \pm 4$ \\
\hline \multicolumn{3}{|l|}{ Work-related features (\%) } \\
\hline Employed & 27 & 28 \\
\hline Unemployed & 6 & 2 \\
\hline Retired & 48 & 58 \\
\hline \multicolumn{3}{|l|}{ Symptoms } \\
\hline Onset of symptoms (year) & $14 \pm 13$ & $16 \pm 13$ \\
\hline Low back pain on walking ${ }^{\dagger}$ & $6.8 \pm 2.4$ & $6.9 \pm 2.4$ \\
\hline $\begin{array}{l}\text { Pain in lower limbs in standing } \\
\text { position }^{\dagger}\end{array}$ & $5.7 \pm 3.1$ & $5.9 \pm 2.5$ \\
\hline Pain in lower limbs on walking ${ }^{\dagger}$ & $6.3 \pm 2.8$ & $6.6 \pm 2.5$ \\
\hline \multicolumn{3}{|l|}{ Functional ability } \\
\hline Oswestry disability index & $35 \pm 14$ & $34 \pm 14$ \\
\hline Reported walking ability (m) & $1,364 \pm 1,826$ & $1,332 \pm 2,027$ \\
\hline $\begin{array}{l}\text { Reported walking ability [median } \\
(25,75 \text { percentile)] }\end{array}$ & $\begin{array}{l}500(400) \\
2,000)\end{array}$ & $\begin{array}{l}500(250 \\
1,750)\end{array}$ \\
\hline
\end{tabular}

Mean values \pm SD unless otherwise stated

${ }^{\dagger}$ Scored on an 11-point numerical scale where 0 represents no pain at all and 10, unbearable pain

* Possible range 0-100, with higher points indicating more severe disability

trunk-muscle endurance and stretching-type exercises. A physiatrist prescribed additional individual physiotherapy consisting of passive treatment modalities (such as ultrasound and TNS) and/or active back exercises to $24 \%$ (10 patients) of the non-operative study group. Bracing was not used, and no forms of invasive treatment, such as local epidural or intra-articular injections, were used either. The patients in the surgical group also received the brochure and the instructions described above.

\section{Statistical analysis}

The analyses were based on the 'intention-to-treat' sample. The data contained repeated measurements of the main response variables. We assumed that dropouts during the follow-up periods could be ignored; in other words, the drop-outs did not bias the results. In the case of continuous response variables (for example the primary outcome), we based the statistical analyses on linear mixed models and, in the case of binary responses, used logistic regression models and generalized estimation equation methods. We calculated several model-adjusted statistics for the different design points. We computed the absolute means and differences for continuous responses, as well as the 
prevalences and relative risks for binary responses. We calculated the confidence intervals using the delta method and tested statistical significance using the Wald test. We did not perform any interim analyses. All $P$ values are twosided. We used two main models. A basic model included the main effects of time and the treatment group and the first-order interactions of time and the treatment group. A more complete model also included the potential confounding factors of sex, education, perceived health status and the hospital. We used this model to control any baseline differences between treatment groups which persisted despite randomisation. We carried out the analyses using the procedures MIXED and GENMOD from the SAS software.

\section{Ethical considerations}

The study was approved by the ethical committees of all the participating hospitals.

\section{Results}

Of the 50 patients who were randomised into the surgical group, four patients were not subjected to surgery and one patient withdrew immediately after the randomisation. Four of the 44 randomised into the non-operative group were operated on during the two-year follow-up examination.

The baseline characteristics of the patients are shown in Table 1. Comprehensive baseline characteristics are shown in the previous publication [18]. The main complaint by patients was pain in the back and lower limbs whilst standing, which was aggravated further by walking. There were no marked differences between the groups in the scores for lower-back pain or lower-limb pain, functional ability (ODI) or walking ability.

At the 6-year follow-up, the following observations were made. For the surgical group, three patients had died, and one patient was lost in the follow-up period. We obtained data for 46 patients out of $50(92 \%)$. The patient who withdrew after randomisation for surgery (Fig. 1) had been operated at 4 years after the randomisation. One patient in the operative group treated by decompression for LSS had been operated on again.

In the non-operative group, three patients had died, and two patients had been lost in the follow-up period. We thus obtained data for 39 patients out of $44(89 \%)$. Four patients in the non-operative group had been subjected to decompressive surgery, all within 2 years of the randomisation. At 6 years, 46 patients in the surgical group and 39 patients in the non-operative group returned the follow-up questionnaires (Fig. 1).
After excluding the six deceased patients (Fig. 1), three from the surgical group and three from the non-operative group, we collected follow-up data on $97 \%$ of the patients at the end of the study after an average of 6 years.

Table 2 shows the mean scores of the ODI, the intensity of leg pain and lower-back pain during walking and reported walking ability during the follow-up period.

Functional ability (ODI) improved in both treatment groups (Table 3, Fig. 2). The global difference during the follow-up favoured the surgical group $(P=0.006)$. Similarly, the inter-group difference in ODI favoured the surgical group at all the follow-up examinations, and at the 72-month follow-up the difference was 9.5 (95\% confidence interval 0.9-8.1). The adjusted mean decreases in ODI scores from baseline to the 72-month follow-up were 8 and $29 \%$ in the non-operative and surgical groups, respectively.

The leg and back pain had improved in both treatment groups at the six-month follow-up, after which the scores levelled off (Table 2; Figs. 3, 4). There was, however, less leg and lower-back pain in the surgical group than in the non-operative group at the 6,12 and 24-month follow-up, but no difference remained at the 6-year follow-up.

Walking ability also improved in both treatment groups during the follow-up, whether recorded by questionnaire (Table 2, Fig. 5) or measured on a treadmill $(6,12$ and 24-month follow-up meetings; [18]). There was no difference between the treatment groups at any follow-up meeting.

\section{Discussion}

The results show that, based on data concerning functional ability (ODI) and perceived back and leg pain, surgical treatment of LSS provided better results than conservative methods of treatment. The favourable effect, with regard to these parameters, was statistically highly significant 12-24 months after operation. The efficacy of surgical treatment slowly declined during the last 4 years of surveillance, but at the 72-month follow-up the ODI results were still superior in the surgically treated group. Walking ability improved considerably in the surgically treated group, but similar improvement was noted also in the nonoperative group.

The length of reported back symptoms preceding inclusion of the patients in our study (14 years), and the walking ability in these patients both at base-line and subsequently are of interest. Patients with LSS frequently report low back pain long before the onset of radicular pain and spinal claudication. Amundsen et al. [1] reported in their series of patients that the median duration of lumbar pain occurred 14 years (range 0-60 years) before treatment 
Table 2 Mean (SD) values of the outcome variables by the time of follow-up in the surgical or non-operative treatment groups
* Number of patients at each follow-up, see Figure 1

* Primary outcome; possible range 0 to 100 , with higher points indicating more severe disability

$\S$ Scored on an 11-point numerical scale where 0 represents no pain at all and 10 , unbearable pain

\begin{tabular}{|c|c|c|c|c|c|}
\hline \multirow[t]{2}{*}{ Outcome variable } & \multirow{2}{*}{$\begin{array}{l}\text { Time } \\
\text { (months) }\end{array}$} & \multicolumn{2}{|c|}{ Non-operative* } & \multicolumn{2}{|c|}{ Surgical* } \\
\hline & & Mean & (SD) & Mean & $(\mathrm{SD})$ \\
\hline \multirow[t]{5}{*}{ Oswestry disability index } & 0 & 34.7 & 14.2 & 34.0 & 14.0 \\
\hline & 6 & 27.3 & 14.0 & 21.4 & 16.1 \\
\hline & 12 & 29.5 & 17.9 & 18.5 & 16.7 \\
\hline & 24 & 27.5 & 17.8 & 20.6 & 16.2 \\
\hline & 72 & 29.8 & 22.1 & 24.2 & 19.7 \\
\hline \multirow[t]{5}{*}{ Leg pain during walking ${ }^{\S}$} & 0 & 6.3 & 2.8 & 6.6 & 2.5 \\
\hline & 6 & 4.5 & 3.2 & 2.7 & 3.2 \\
\hline & 12 & 4.5 & 3.1 & 2.8 & 3.1 \\
\hline & 24 & 4.5 & 3.0 & 2.9 & 3.0 \\
\hline & 72 & 4.1 & 3.1 & 4.2 & 3.3 \\
\hline \multirow[t]{5}{*}{ Low back pain during walking ${ }^{\S}$} & 0 & 6.8 & 2.4 & 6.9 & 2.4 \\
\hline & 6 & 5.4 & 2.8 & 2.9 & 3.0 \\
\hline & 12 & 5.1 & 2.9 & 2.8 & 3.0 \\
\hline & 24 & 4.8 & 2.8 & 2.7 & 2.7 \\
\hline & 72 & 4.4 & 3.1 & 4.1 & 3.4 \\
\hline \multirow[t]{5}{*}{ Self-reported walking ability (m) } & 0 & 1,364 & 1,826 & 1,332 & 2,028 \\
\hline & 6 & 2,786 & 3,160 & 2,905 & 2,753 \\
\hline & 12 & 2,759 & 3,250 & 3,186 & 2,959 \\
\hline & 24 & 2,767 & 2,880 & 2,982 & 3,099 \\
\hline & 72 & 3,554 & 3,987 & 2,844 & 3,305 \\
\hline \multirow{5}{*}{$\begin{array}{l}\text { Self-reported walking ability median } \\
(25,75 \text { percentile })\end{array}$} & 0 & \multicolumn{2}{|c|}{$500(400,2,000)$} & \multicolumn{2}{|c|}{$500(250,1,750)$} \\
\hline & 6 & \multicolumn{2}{|c|}{$2,000(500,5,000)$} & \multicolumn{2}{|c|}{$2,000(1,000,4,500)$} \\
\hline & 12 & \multicolumn{2}{|c|}{$1,000(500,5,000)$} & \multicolumn{2}{|c|}{$2,000(1,000,5,000)$} \\
\hline & 24 & \multicolumn{2}{|c|}{$2,000(500,5,000)$} & \multicolumn{2}{|c|}{$2,000(1,000,4,000)$} \\
\hline & 72 & \multicolumn{2}{|c|}{$1,200(500,6,500)$} & \multicolumn{2}{|c|}{$1,250(500,5,000)$} \\
\hline
\end{tabular}

Table 3 Adjusted mean (SE) Oswestry disability index in the surgical or non-operative treatment groups, mean differences (95\% CI) between the treatment groups, and per cent mean change (95\% CI) by time of follow-up

\begin{tabular}{|c|c|c|c|c|c|c|c|c|c|c|c|}
\hline \multirow[t]{3}{*}{ Time (months) } & \multirow{2}{*}{\multicolumn{2}{|c|}{ Non-operative* }} & \multirow{2}{*}{\multicolumn{2}{|c|}{ Surgical* }} & \multirow{2}{*}{\multicolumn{2}{|c|}{ Difference }} & \multirow[t]{3}{*}{$P^{\dagger}$} & \multicolumn{4}{|c|}{$\%$ Change } \\
\hline & & & & & & & & \multicolumn{2}{|c|}{ Non-operative } & \multicolumn{2}{|c|}{ Surgical } \\
\hline & Mean & (SE) & Mean & (SE) & Mean & $(95 \% \mathrm{CI})$ & & Mean & $(95 \% \mathrm{CI})$ & Mean & $(95 \% \mathrm{CI})$ \\
\hline 0 & 36.0 & (2.0) & 32.9 & (1.8) & 3.2 & $(-2.2$ to 8.6$)$ & & 0 & & 0 & \\
\hline 6 & 29.6 & (2.3) & 19.7 & (2.1) & 9.9 & (3.8 to 15.0 ) & & 18 & (6 to 30 ) & 42 & $(29-54)$ \\
\hline 12 & 31.7 & (2.5) & 17.8 & (2.3) & 13.8 & (7.1 to 20.5 ) & 0.006 & 13 & (0 to 25$)$ & 48 & $(35-60)$ \\
\hline 24 & 30.3 & $(2.5)$ & 20.2 & (2.3) & 10.2 & (3.5 to 16.8 ) & & 16 & (4 to 29 ) & 40 & $(27-53)$ \\
\hline 72 & 33.3 & (3.2) & 23.8 & (3.0) & 9.5 & $(0.9$ to 18.1$)$ & & 8 & ( -7 to 23$)$ & 29 & $(13-45)$ \\
\hline
\end{tabular}

Model: group, time, group time, sex, hospital, education, perceived health

Primary outcome; possible range $0-100$, with higher points indicating more severe disability

* Number of patients at each follow-up, see Figure 1

${ }^{\dagger} P$ value for global difference between the treatment groups during the entire follow-up period

started, and that the mean duration of radicular pain before treatment was 2 years (range 0-37 years). This tallies with our baseline data [18]. We did not, however, separately specify the onset of radicular pain.

A narrow lumbar spinal canal seems to predispose to spinal claudication [2, 4, 12, 15, 21]. Schönström et al. [20] constricted the human cauda equina and simultaneously measured the ensuing pressure on the neural elements on different lumbar segmental levels. Increasing pressure on the nerve roots seemed to depend on the size of the lumbar spinal canal, measured as the minimum cross-sectional area (mCSA). It was estimated that a mCSA between 70 and 


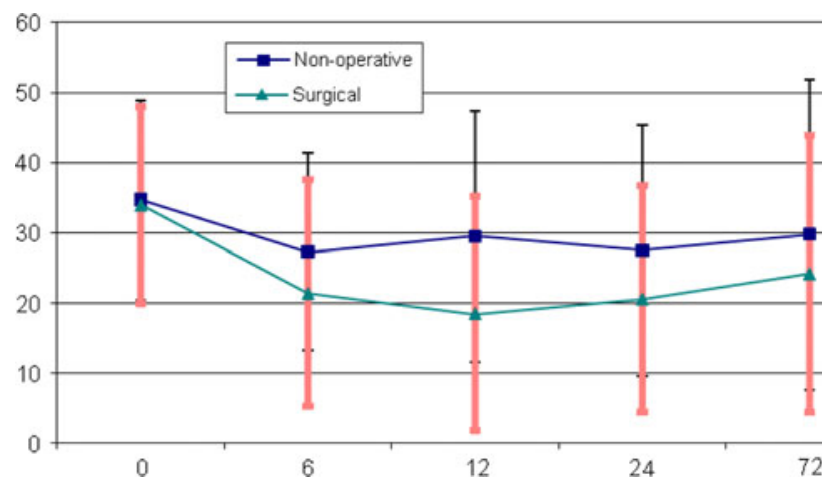

Fig. 2 Mean scores ( \pm standard deviation as a vertical bar) of the Oswestry disability index (scale 0-100) in the surgical and nonoperative treatment groups during the 72-month follow-up

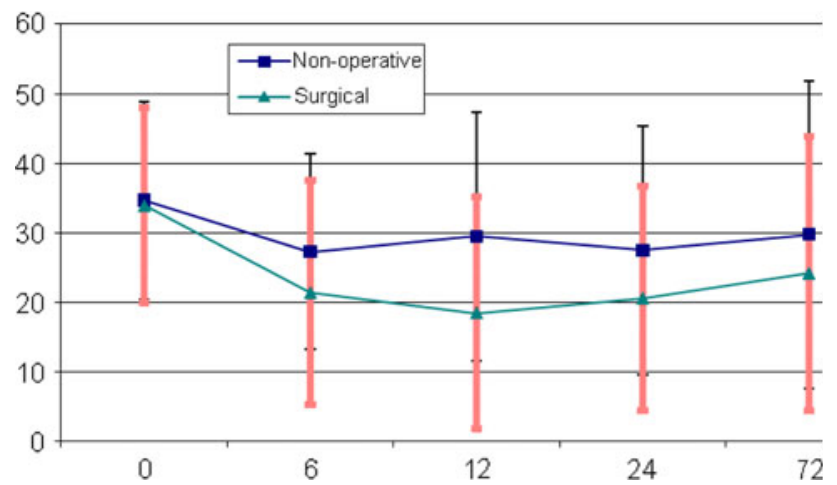

Fig. 3 Mean intensity ( \pm standard deviation as a vertical bar) of the leg pain during walking (numerical scale, $0-10$ ) in the surgical and non-operative treatment groups during the 72 -month follow-up

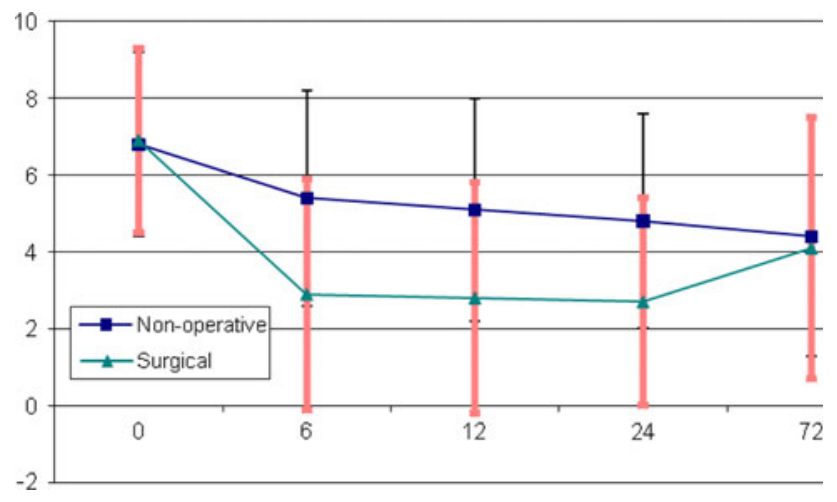

Fig. 4 Mean intensity ( \pm standard deviation as a vertical bar) of back pain during walking (numerical scale, $0-10$ ) in the surgical and nonoperative treatment groups during the 72-month follow-up

$80 \mathrm{~mm}^{2}$ may be regarded a borderline area, above which signs of neural encroachment are unlikely. In a recent study Ogikubo et al. [19] showed a relationship between the mCSA-values and walking ability in patients with LSS: patients who could walk less than $500 \mathrm{~m}$ had an average mCSA significantly smaller $\left(53.5 \mathrm{~mm}^{2}\right)$ than that recorded

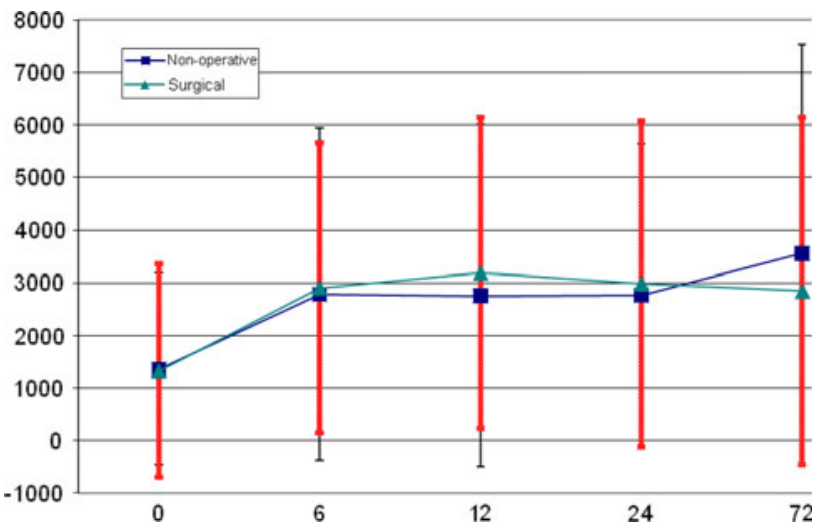

Fig. 5 Mean ( \pm standard deviation as a vertical bar) of reported walking ability in metres in the surgical and non-operative treatment groups during the 72-month follow-up

in patients who could walk $500 \mathrm{~m}$ or more $\left(68.8 \mathrm{~mm}^{2}\right)$. They concluded that the latter combination of walking restriction and mCSA indicates the borderline between moderate and severe symptoms. In our study the mCSA was $52.2 \mathrm{~mm}^{2}$ in the surgically treated group and $51.6 \mathrm{~mm}^{2}$ in the nonoperatively treated group, which suggests more encroachment on the neural elements than that reported by Ogikubo et al. [19].

Decompression of the neural elements is the primary purpose of the operation for spinal stenosis in cases of lumbar instability complemented with a lumbar fusion. We noted concomitant degenerative spondylolisthesis in $41 \%$ of the patients treated surgically, of which ten patients were treated initially by instrumented lumbar fusion [18]. The present series are too small in number to warrant further statistical analysis of the minute outcome difference between instrumented fusion and mere decompression found at the 2-year follow-up examination. The strength of the present study is threefold: first, it focuses on a patient population which comprises two congruous groups of patients with LSS of similar seriousness, randomized into a surgical and a non-operative treatment group; second, the adherence to treatment assignments throughout the study; and third, the high patient attendance to scheduled followup examinations. The weakness of the study is the shortage of statistical power in the small series of patients, which limited our capacity to identify predictive factors regarding treatment outcomes for these patients.

In two large randomised trials by Weinstein et al. [22, 24], one trial recruited patients with combined spinal stenosis and degenerative spondylolisthesis and another trial recruited patients with spinal stenosis only [23]. There was considerable crossover between the treatment arms in both trials and, consequently, in the intention-to-treat analysis no inter-group differences were found in the primary outcomes. The as-treated analyses as well as the analyses on 
the concomitant non-randomised cohorts showed the effectiveness of surgery on the primary outcomes of bodily pain, physical function and ODI. The non-adherence to treatment assignments makes interpretation of the results in the trials by Weinstein et al. difficult [6]. However, the results are in accordance with those of the present study at the 2-year follow-up. In the as-treated analysis at the 4-year follow-up for the trial by Weinstein et al. [24] on combined spinal stenosis and degenerative spondylolisthesis, the effect in favour of surgery was maintained in all the primary outcomes. Our findings on spinal-stenosis patients, with or without degenerative spondylolisthesis, differ from these results at the 6-year follow-up, as we found a difference in favour of surgery only in the ODI.

Also, the present study corroborates other reports on the treatment outcomes. Long-term outcome analyses of LSS show satisfactory results after surgical decompressionmore so than after non-operative measures. Thus, Atlas et al. [3] found that the outcomes at 1 and 4 years after surgery favoured initial surgical treatment, whereas outcome differences between surgical and non-operative treatment groups after 8-10 years were no longer discernible. Amundsen et al. [2] studied 100 patients with symptomatic LSS subjected to either surgical or nonoperative measures. Of these patients, 31 were randomised into a surgical group or a non-operative group. At the 10-year follow-up, they concluded that surgery was a good treatment for four-fifths of severely afflicted patients and that non-operative treatment yielded satisfactory results in about $70 \%$ of the patients.

After Verbiest's observation on narrow spinal canal syndromes [21], recent studies have questioned the presumed close correlation between radiographic findings on the one hand and signs and symptoms on the other [2, 17]. In current clinical practice the choice of either surgical or non-operative treatment seems to depend mainly on the severity of the symptoms, not on the degree of narrowing. However, overall clinical judgment is demanding; experienced surgeons asked to assess plain CT-scans regarding the presence or absence of LSS achieved only a moderate level of agreement; and, faced with the task of assessing the severity of spinal stenosis, the inter-observer agreement fell to a poor level [10]. Similarly, surgeons achieved only a mediocre, moderate level of inter-observer agreement when assessing MR imaging findings for the lumbar spine [5]. There is an obvious need for further studies aiming at a standard classification of LSS, and for efforts to clarify the indications for surgery.

The number of LSS operations in various countries is increasing, partly due to ageing of the population [7, 9, 13]. Our results suggest that patients with moderate LSS could also initially be offered non-operative treatment for 2 years, as, during this period of surveillance, only one out of ten patients needed operative treatment. It should be noted that in the non-operative group no further surgical decompression procedures were noted during the ensuing 4 years of surveillance. However, patients assigned to surgical treatment did better during these first 2 years with regard to both pain and functional ability. After 72 months, only the functional ability of the patients was better in the surgical group. We propose that, before surgical intervention for moderate spinal stenosis, the course of the disease should be duly followed and any final decision to operate should be based on discussions with the patient, including providing the patient with information on the natural course of the disease and the anticipated effects of surgery based on randomised trials.

Acknowledgments Supported by the Finnish Office for Health Care Technology Assessment and the participating hospitals.

\section{References}

1. Airaksinen O, Herno A, Turunen V, Saari T, Suomalainen O (1997) Surgical outcome of 438 patients treated surgically for lumbar spinal stenosis. Spine 22:2278-2282

2. Amundsen T, Weber H, Nordal HJ, Magnaes B, Abdelnoor M, Lilleås $\mathrm{F}$ (2000) Lumbar spinal stenosis: conservative or surgical management? Spine 25:1424-1436

3. Atlas SJ, Keller RB, Robson D, Deyo RA, Singer DE (2000) Surgical and nonsurgical management of lumbar spinal stenosis: four-year outcomes from the Maine lumbar spine study. Spine 25:556-562

4. Atlas SJ, Keller RB, Wu YA, Deyo RA, Singer DE (2005) Longterm outcomes of surgical and nonsurgical management of lumbar spinal stenosis: 8 to 10 year results from the Maine Lumbar Spine Study. Spine 30:936-943

5. Carrino JA, Lurie JD, Tosteson ANA et al (2009) Lumbar spine: reliability of MR imaging findings. Radiology 249(3):161-170

6. Chou R, Baisden J, Carragee EJ, Resnick DK, Schaffer WO, Loeser JD (2009) Surgery for low back pain. A review of the evidence for an American pain society clinical practice guideline. Spine 10:1094-1109

7. Ciol MA, Deyo RA, Howell E et al (1996) An assessment of surgery for spinal stenosis: time trends, geographic variations, complications, and reoperations. J Am Geriatr Soc 44:285-290

8. Cornefjord M, Byrod G, Brisby H, Rydevik B (2000) A long-term (4- to 12-year) follow-up study of surgical treatment of lumbar spinal stenosis. Eur Spine J 9:563-570

9. Deyo R, Gray D, Kreuter W et al (2005) United States trends in lumbar fusion surgery for degenerative conditions. Spine 30:1441-1445

10. Drew B, Bhandari M, Kulkarni AV, Louw D, Reddy K, Dunlop B (2000) Reliability in grading the severity of lumbar spinal stenosis 13:253-258

11. Fairbank J, Couper J, Davies J, O’Brien JP (1980) The Oswestry low back pain disability questionnaire. Physiotherapy 8:271-273

12. Hansraj KK, O'Leary PF, Cammisa FP Jr, Hall JC, Fras CI, Cohen MS, Dorey FJ (2001) Decompressive surgery for typical lumbar spinal stenosis. Clin Orthop 384:10-17

13. Jansson K- $\AA$, Németh G, Granath F, Jönsson B, Blomqvist P (2009) Health-related quality of life (EG-5D) before and one year after surgery for lumbar spinal stenosis. J Bone Jt Surg (Br) 91-B:211-216 
14. Johnsson KE, Rosen I, Uden A (1992) The natural course of lumbar spinal stenosis. Clin Orthop 279:82-86

15. Jönsson B, Annertz M, Sjöberg C, Strömqvist B (1997) A prospective and consecutive study of surgically treated lumbar spinal stenosis. Spine 22:2938-2944

16. Katz JN, Lipson SJ, Chang LC, Levine SA, Fossel AH, Liang MH (1996) Seven- to 10-year outcome of decompressive surgery for degenerative lumbar spinal stenosis. Spine 21:92-98

17. Lohman CM, Tallroth K, Kettunen J, Lindgren KA (2006) Comparison of radiologic signs and clinical symptoms of spinal stenosis. Spine 31:1834-1840

18. Malmivaara A, Slätis P, Heliövaara M, Sainio P, Kinnunen H, Kankare J, Dalin-Hirvonen N, Seitsalo S, Herno A, Kortekangas P, Niinimaki T, Rönty H, Tallroth K, Turunen V, Knekt P, Härkänen T, Hurri H, Finnish Lumbar Spinal Research Group (2007) Surgical or nonoperative treatment for lumbar spinal stenosis? A randomized controlled trial. Spine 32:1-8

19. Ogikubo O, Forsberg L, Hansson T (2007) The relationship between the cross-sectional area of the cauda equina and the preoperative symptoms in central lumbar spinal stenosis. Spine 32:1423-1428

20. Schönström N, Hansson T (1988) Pressure changes following constriction of the cauda equina Spine 13:385-388
21. Verbiest H (1954) A radicular syndrome from developmental narrowing of the lumbar vertebral canal. J Bone Joint Surg Br 36-B:230-237

22. Weinstein JN, Lurie JD, Tosteson TD, Hanscom B, Tosteson AN, Blood EA, Birkmeyer NJ, Hilibrand AS, Herkowitz H, Cammisa FP, Albert TJ, Emery SE, Lenke LG, Abdu WA, Longley M, Errico TJ, Hu SS (2007) Surgical versus nonsurgical treatment for lumbar degenerative spondylolisthesis. $N$ Engl J Med $356: 2257-2270$

23. Weinstein JN, Tosteson TD, Lurie JD, Tosteson AN, Blood E, Hanscom B, Cammisa F, Albert T, Boden SD, Hilibrand A, Goldberg H, Berven S, An H, SPORT Investigators (2008) Surgical versus nonsurgical therapy for lumbar spinal stenosis. N Engl J Med 358:794-810

24. Weinstein JN, Lurie JD, Tosteson TD, Zhao W, Blood EA, Tosteson AN, Birkmeyer N, Herkowitz H, Longley M, Lenke L, Emery S, Hu SS (2009) Surgical compared with nonoperative treatment for lumbar degenerative spondylolisthesis. Four-year results in the spine patient outcomes research trial (SPORT) randomized and observational cohorts. J Bone Joint Surg [Am] 91:1295-1304 